\title{
FULL SCALE TESTS OF THE BASE-ISOLATION SYSTEM FOR AN EMERGENCY HOSPITAL
}

\author{
M.F. Ferrotto ${ }^{1}$, L. Cavaleri $^{1}$, F. Di Trapani ${ }^{2}$ and P. Castaldo ${ }^{2}$, \\ ${ }^{1}$ Università degli Studi Palermo, Department of Engineering,Viale delle Scienze 90128 Palermo, Italy \\ e-mail:\{liborio.cavaleri, marcofilippo.ferrotto\}@unipa.it \\ ${ }^{2}$ Politecnico di Torino, Department of Structural, Geotechnical and Building Engineering \\ Corso Duca degli Abbruzzi 10129 Torino, Italy \\ e-mail: \{paolo.castaldo, fabio.ditrapani\}@ polito.it
}

\begin{abstract}
The paper presents the results of some full-scale tests regarding the base-isolation system of the emergency room building of the polyclinic hospital in Palermo (Italy). This building has been recently realized and its base isolation system is characterized by double friction pendulum isolators. Static lateral pushing tests were aimed at identifying fundamental mechanical properties of the whole isolation level (e.g. friction forces and stiffness) in order to verify the agreement with the design hypotheses. Further dynamic tests provided different displacements of the isolated base followed by the instantaneous release (snap-back tests), in order to verify the effectiveness, the mechanical parameter in dynamics and re-centering capacity of the isolation system. The design of both the types of test and the respective results and interpretations are illustrated in the paper highlighting a number of issues arising when arranging such kind of investigations on full scale buildings.
\end{abstract}

Keywords: Friction pendulum bearing, seismic isolation, snap-back test, friction, in-situ testing, full-scale experimental tests. 


\section{INTRODUCTION}

Friction pendulum isolators (FPIs) have been widely used in the last decades for several applications for the seismic protection of strategic structures such as bridges, emergency buildings, hospitals, etc, in high-risk seismic areas and sometimes for residential buildings [1]. The advantages in the adoption of this kind of seismic isolation systems is due to the high dissipative capacity, the possibility of obtaining a mass independent period of the superstructure and, the durability; the re-centering capacity is entrusted to the geometric configuration of the isolator curved sliding surfaces [2-3].

Despite the static and dynamic behavior of these systems has been deepen analyzed in the recent years also by the experimental point of view [4-8], very few studies about the in-situ behavior of structures equipped with FPIs are available nowadays.

The actual dynamic behavior of base-isolated structures can be investigated by quick release tests, more generally called snap back tests. This approach is well suited because the movement of the structure requires a quantity of energy obtainable without excessive difficulties, allowing to observe the dynamic behavior according to the design displacement values. In detail, the structure is moved (pushed) to a given value of displacement - e.g. corresponding to a certain Limit State - and sudden released causing free vibrations. In this way, the performances of the isolation devices can be observed, comparing the in-situ behavior with that of the design provisions.

In the last decades, a number of field tests on base-isolated structures were successfully carried out [9-16]. Among the most relevant available studies, Braga and Laterza [11] performed a series of dynamic snap-back tests on a residence building mounted on a hybrid isolation system, having sliding bearings for isolation and steel rubber bearings to have a recentering force. The in-situ dynamic behavior of the structure was compared with experimental shear tests on the isolator devices.

He et al. [15] carried out ambient vibration tests, free attenuation vibration tests, sinusoidal vibration tests and displacement controlled earthquake simulation tests on a laminated rubber bearings (LNR) and lead rubber bearing (LRB) base-isolated 15-story steel structure in Kunming city, China.

Gesualdi et al. [16] presented the results of in-situ release tests carried out on a rubber bearing and a flat sliding bearing of a 3-storey base-isolated reinforced concrete frame building located in the city of Augusta, Sicily. The authors used the results of ambient vibration and release tests to calibrate numerical models, performing reliable dynamic analyses and comparing the results with that of the design seismic performances.

What above described highlights the role attributed to seismic isolation systems that, when possible, are preferred to seismic resisting structures exploiting the ductility capacity or the contribution of infills [17-20] or to an improvement of strength and ductility by means of traditional retrofitting systems [21-23], or to passive dissipation devices [24-26].

In this paper, a series of quasi-static and dynamic snap-back tests carried out on the baseisolated new emergency room building of the university polyclinic hospital of Palermo are described and discussed. The isolated structure was realized on double curved friction pendulum isolators.

Static lateral pushing tests were aimed at identifying the fundamental mechanical properties of the whole isolation system (e.g. friction forces and stiffness) in order to verify the agreement with the design hypotheses. Further dynamic tests consisted of imposing different displacements at the isolated level and then instantaneously releasing, in order to verify its effectiveness, to measure its dynamical properties and to observe the re-centering capacity. 
The design of the field testing, comprising the thrust mechanical device and the reaction wall is described along the paper followed by the description of the in-situ testing and its main results.

\section{DESCRIPTION OF THE STRUCTURE}

The building has a non-regular plan with a 5-sided polygonal shape. It has a length of 46.3 $\mathrm{m}$ and a maximum width of $21.3 \mathrm{~m}$. The isolated superstructure has 3 floors with an interstorey height of about 4 meters. The superstructure is steel framed, characterized by 41 columns made of HEB 300 steel profiles in agreement to the classification of Eurocode 3 . The rigid base on the isolators is a reinforced concrete plate as for the slabs of the superstructure. The substructure is characterized by reinforced concrete columns on a slab foundation. Fig.1 shows a vertical section of the building.

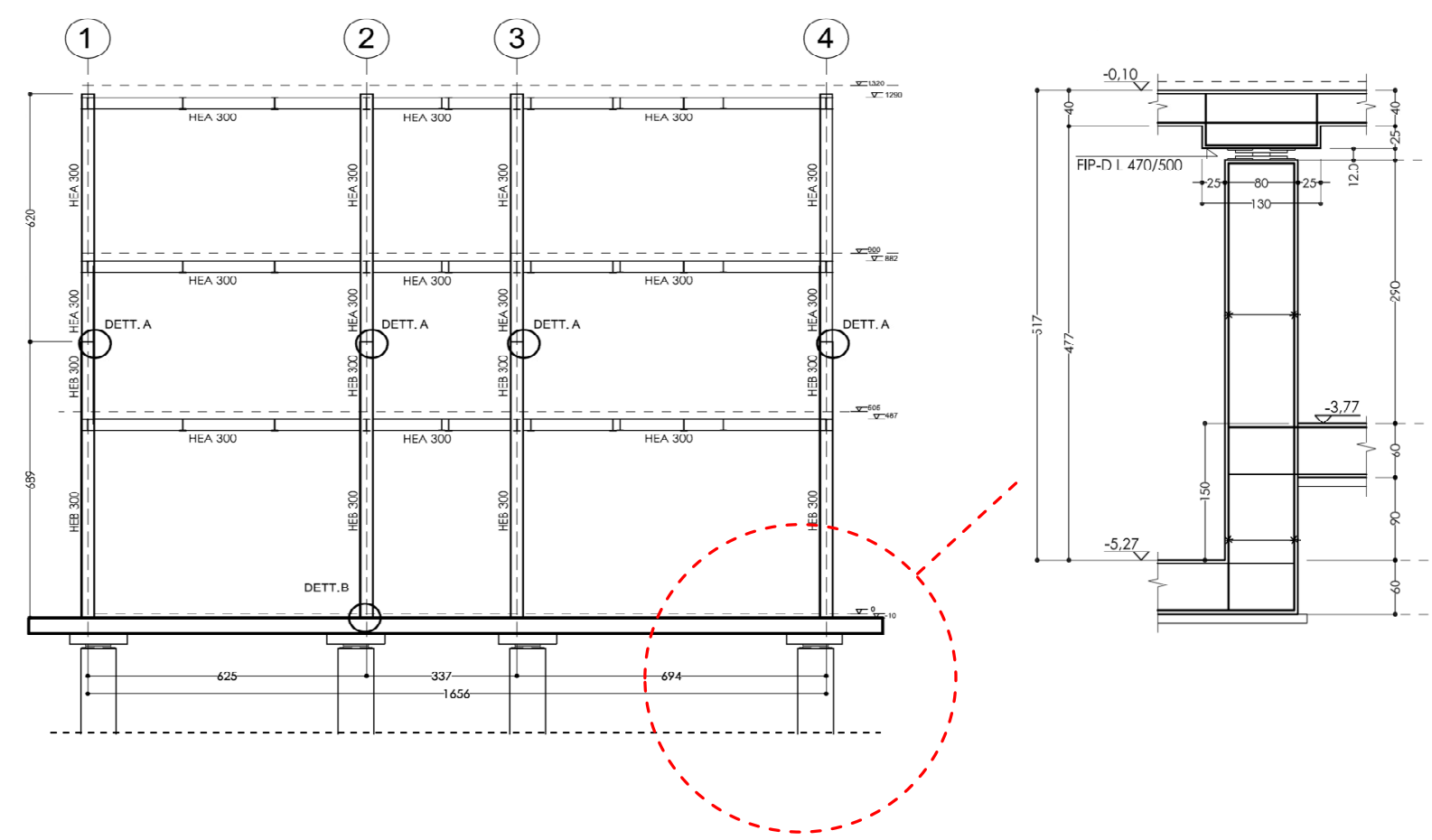

Figure 1: Vertical section of the building structure

Appropriate joints divide the building in question along three sides from fixed base buildings (Figs. 2-3).

The isolated building was realized on 41 double curved friction pendulum isolators with the same radius of curvature. Among them, 15 isolators have a bearing capacity of $1000 \mathrm{kN}$, 20 have a bearing capacity of $1500 \mathrm{kN}$ and 6 have a bearing capacity of $2000 \mathrm{kN}$. Each isolator is characterized by:

1. minimum friction coefficient $(\mu): 0.025$;

2. radius of curvature $(\mathrm{R}): 2500 \mathrm{~mm}$;

3. maximum horizontal displacement: $\pm 250 \mathrm{~mm}$;

4. force-displacement behavior: rigid-plastic with hardening type

The variation of the dynamic friction coefficient is expressed by the producer according to the following equation: 


$$
\mu=2.5\left(\frac{N_{S d}}{N_{E d}}\right)^{-0.834}
$$

being $\mathrm{N}_{\mathrm{Sd}}$ the vertical load acting on the isolator and $\mathrm{N}_{\mathrm{Ed}}$ the vertical load capacity. The positioning of the isolators and the pushing device is shown in Fig. 3.
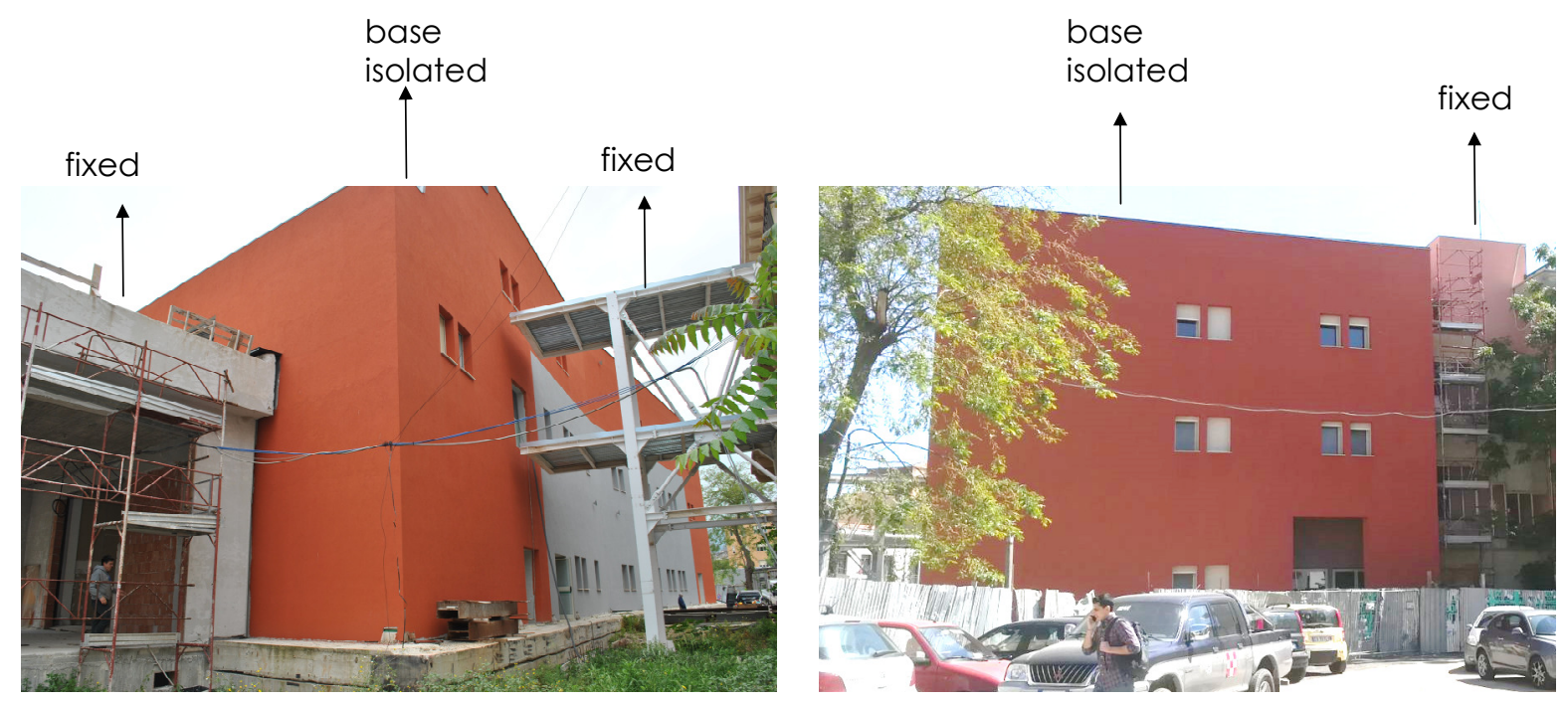

Figure 2: The emergency room building of the polyclinic hospital

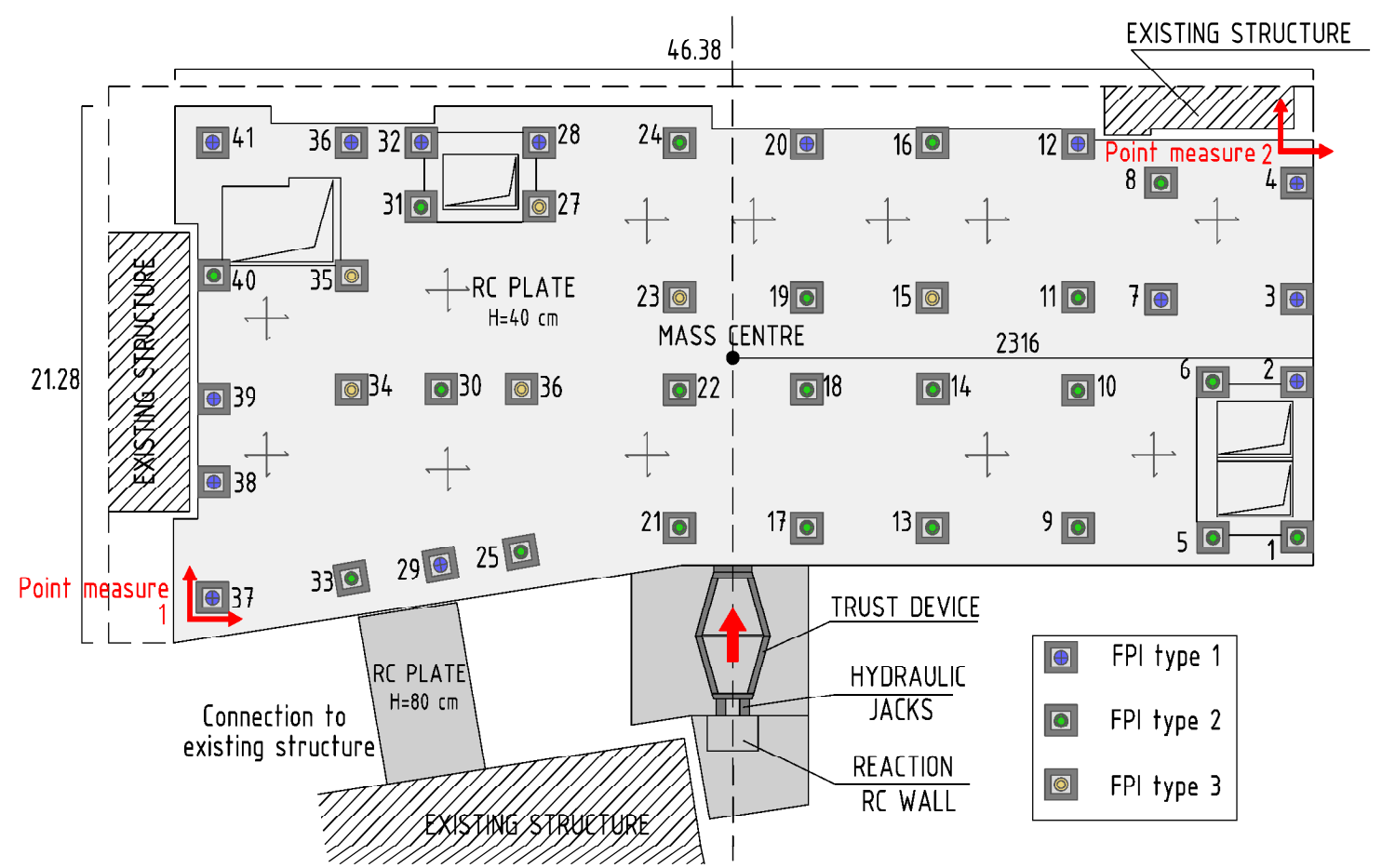

Figure 3: Location of the isolators and of the pushing device 


\section{TEST SETUP AND MEASUREMENT SYSTEMS}

Quasi-static and the snap-back tests were carried out. The direction of the load was established to be orthogonal to the longest side of the building, for which the steel columns provide the high stiffness contribution. The application point of the load was set in correspondence to the center of mass of the structure nominally corresponding to the stiffness center of the isolation system according to the data provided by the design (Fig. 3).

The thrust load was applied through two single-acting cylinders with a nominal load of 240 tons and a thrust device. The force was obtained by measuring the pressure in the hydraulic circuit of the jacks.

The thrust device consisted of 6 consecutive pin jointed steel rods constituting a hexagon. Two non-consecutive nodes of this hexagon were connected by a steel bar (fuse) arranged orthogonally to the thrust direction and in a barycentric position with respect to the device itself (Fig.4). The latter was designed to fail for a fixed design force or to prevent any fail depending on the type of test (snap-back or static push without release). The force applied to the fuse can be easily determined depending on the geometric configuration. In the case of snap-back test, after the pushing leading the structure to a given value of displacement, the fuse fails causing immediately an uniform distribution of accelerations along the building height.

The structural response was recorded by means of a set of displacement transducers and a set of accelerometers placed at each floor. Moreover, a set of reflecting prisms were arranged at each floor for the measurement of the displacements by a laser vibrometer. The above prisms were located at the intersection of the building face with the vertical plane containing the thrust direction. The displacements of the rigid base were also measured using electronic gauges (position shown in Fig. 3) able to transfer data to a control unit for wireless data acquisition. The acquisition frequency of the electronic gauges was $0.5 \mathrm{~Hz}$ while the acquisition frequency of the laser vibrometer was $170 \mathrm{~Hz}$.

\section{LATERAL PUSHING AND SNAP-BACK TESTS}

\subsection{Preliminary assessment}

In order to prevent any structural damage, the test was designed to reach a lateral displacement corresponding to the serviceability limit state (SLS), establishing a maximum displacement of $150 \mathrm{~mm}$ against a maximum displacement capacity of $250 \mathrm{~mm}$. Since the actual friction coefficient as well as the exact value of the mass of the structure was unknown, the forces involved (thrusting force and friction force) were evaluated at each target displacement. In detail, different steps of displacement with $25 \mathrm{~mm}$ of interval were defined, starting from 0 to $150 \mathrm{~mm}$. For each value of displacement, the equivalent stiffness of the system (and consequently the push force) and the re-centering force were obtained. In order to do this an estimation of the weight of building was preliminary done while the most conservative values of the friction coefficient declared by the producer. The estimation of the forces involved allowed the dimensioning of the thrusting device and of the reaction wall but also the evaluation of the compatibility of the response with the limit serviceability state. 

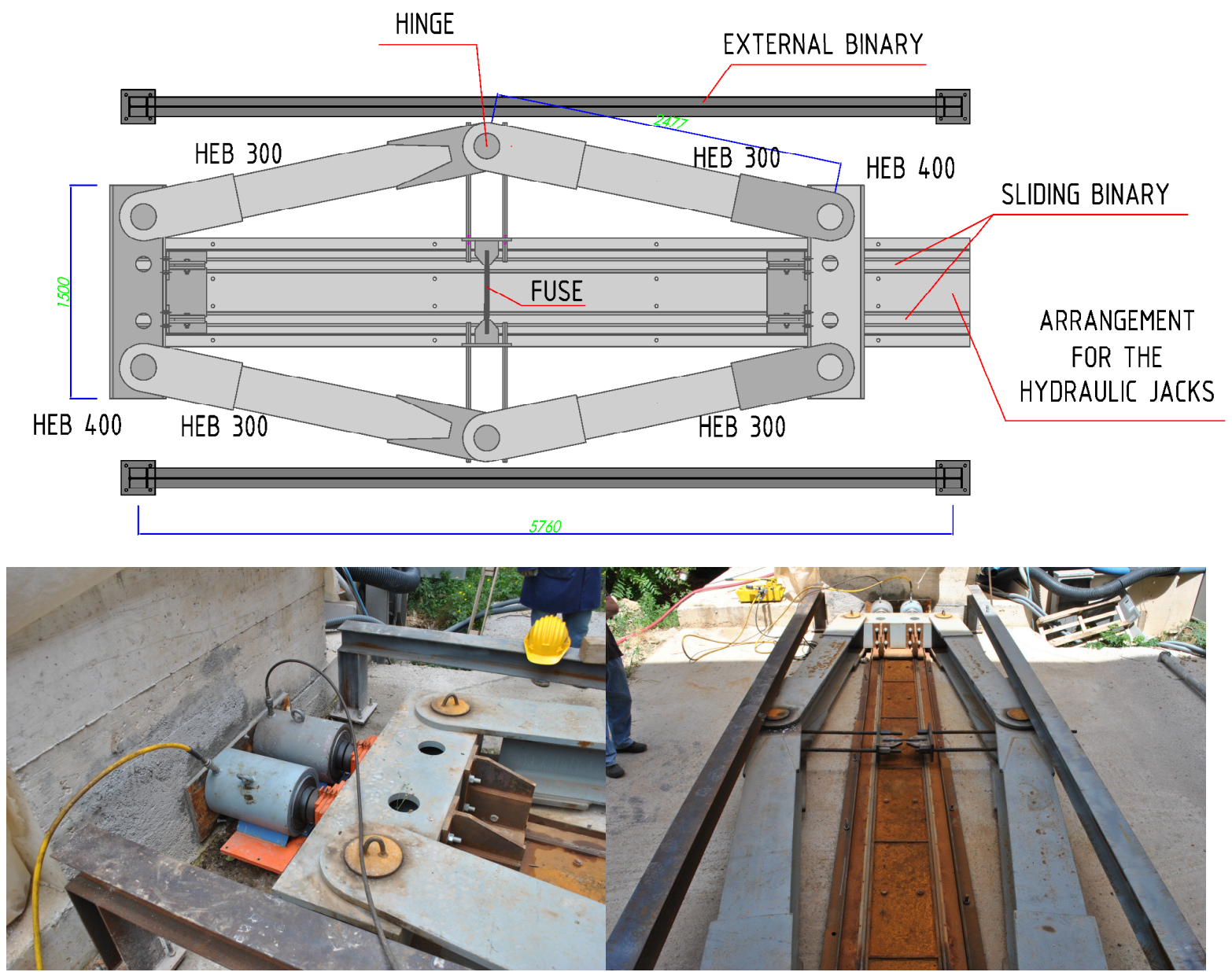

Figure 4: Details of the thrust device.

In the preliminary estimation it was considered the restoring force model typical of a pendulum system, that is:

$$
F_{R}=\frac{W \cdot s}{R}
$$

where $F_{R}$ is the restoring force (that is a rate of the pushing force), $s$ is the displacement and $R$ is the radius of curvature of the bearing device, $\mathrm{W}$ is the building weight.

Further, the resisting force $F_{\text {thrust }}$ during the pushing, because of the friction, was assumed as

$$
F_{\text {thrust }}=d \sum_{j=1}^{n} N_{s d, j}\left(\frac{\mu_{j}}{s}+\frac{1}{R}\right)
$$

where $N_{s d, j}$ is the vertical load acting on the $\mathrm{j}$-th isolator and $\mu_{j}$ is the friction coefficient exhibited by the $\mathrm{j}$-th isolator accordingly with Eq. (1).

If it is assumed the same friction coefficient for each isolator then Eq.(3) becomes

$$
F_{\text {thrust }}=W \cdot s\left(\frac{\mu}{s}+\frac{1}{R}\right)
$$


Also, the instantaneous stiffness becomes

$$
K_{\text {inst }}=W\left(\frac{\mu}{s}+\frac{1}{R}\right)
$$

From Eq. 5 it derives the coincidence of the center of stiffness and the center of mass. The recentering force $\left(F_{r e c}\right)$, that is a pull force, because of a uniform friction, can be obtained as:

$$
F_{r e c}=W\left(\mu-\frac{s}{R}\right)
$$

Assumed a first attempt value of the weight of the structure of $25000 \mathrm{kN}$, it was possible to evaluate the load acting on each single bearing device and the corresponding friction coefficient. Then, an average value of the friction coefficient was calculated and preliminary analytical evaluation of the thrust loads and the re-centering forces was made to estimate the expected level of forces to be achieved during the field testing.

The above mentioned characteristics obtained for each level of displacement are shown in Tab. 1. It is possible to verify that, based on the preliminary evaluations; the self-re-centering function is activated for a displacement value of about $125 \mathrm{~mm}$. For lower values of displacement, to bring the building back to the initial configuration, it is necessary to move it with the aid of an external device that applies the necessary re-centering force.

\begin{tabular}{llll}
\hline $\mathrm{s}$ & $\mathrm{K}_{\text {inst }}$ (Eq. 5) & $\mathrm{F}_{\text {thrust }}($ Eq. 4) & $\mathrm{F}_{\text {rec }}$ (Eq. 6) \\
{$[\mathrm{mm}]$} & {$[\mathrm{kN} / \mathrm{mm}]$} & {$[\mathrm{kN}]$} & {$[\mathrm{kN}]$} \\
\hline 50 & 34.5 & 1725.7 & 795.8 \\
75 & 26.3 & 1970.4 & 600.0 \\
100 & 22.2 & 2627.2 & 335.31 \\
125 & 19.7 & 3284.1 & 110.6 \\
150 & 18.0 & 3940.9 & 0 \\
\hline
\end{tabular}

Table 1: Mechanical characteristics of the isolated structure at given displacements and loads.

The above characteristics were used to evaluate the force levels to be used during the field testing in order to move the structure to the established displacements. The actual values of the friction coefficients (static and dynamic) and the weight of the structure were determined thank to the in-situ testing.

In the case of the snap-back tests, once the values of accelerations at the moment of release were recorded, the values of the initial friction coefficient were determined according to the following equation of motion:

$$
M \cdot \ddot{s}+F_{R}+W \cdot \mu \cdot \operatorname{sign}(\dot{s})=0
$$

where $M$ is the mass of the system, $F_{R}$ is the restoring force (Eq. 2), $W$ is the building weight and $\mu$ is the average friction coefficient. In addition, the average friction coefficient from the time of release to the stop (dynamic friction coefficient) was obtained by the following energy balance: 


$$
\begin{aligned}
E_{p i} & =E_{d}+E_{p f} \\
E_{p i}=0.5 \frac{\mathrm{W} \cdot \mathrm{s}_{0}{ }^{2}}{R} ; \quad E_{d} & =\mu \cdot \mathrm{W} \cdot \mathrm{s}_{i} ; \quad E_{p f}=0.5 \frac{\mathrm{W} \cdot \mathrm{s}_{f}{ }^{2}}{R}
\end{aligned}
$$

being $E_{p i}$ the initial potential energy, $E_{d}$ the dissipated energy by friction and $E_{p f}$ the final potential energy, depending on the initial displacement $s_{0}$ (at the moment of release) and on the final residual displacement $s_{f}$.

\subsection{Results: quasi-static tests}

Two quasi-static lateral pushing tests were carried out to evaluate:

1) the actual weight of the superstructure;

2) the mechanical characteristics of the base isolation system (static friction coefficient);

3) the actual thrusting force to be applied for the reaching of the target displacement in the snap-back test ;

4) the strength of the fuse to be chosen basing on the actual thrusting force.

During the first test the structure was pushed up to an average displacement (mean in the direction of the thrust of the displacements measured at points A and B of Fig. 5 - the same points are called 1 and 2 in Fig.3) of about $97.6 \mathrm{~mm}$, after which a slow discharge was carried out and the structure moved back showing a residual displacement of approximately $92 \mathrm{~mm}$. The thrust was subsequently increased again until a mean displacement of $130.12 \mathrm{~mm}$ was achieved. After the unloading the residual displacement was $85 \mathrm{~mm}$.

Fig. 5 shows both the displacements of the measurement points $\mathrm{A}$ and $\mathrm{B}$ and the average displacement. The average friction coefficient of first detachment and the average friction coefficient after the first detachment are reported in Fig. 5. The first is calculated by referring to the effective force of first detachment while the second is calculated based on the idealized model (Eq.4) fitting the experimental results. It is possible to note that, during the pushing, the building exhibited a clockwise rotation. This effect was probably caused by a different ratio between capacity and demand in terms of vertical load on each isolator which determined different coefficient of friction for each isolator (Eq.(1)). As a consequence, the stiffness center resulted in a position different from that of the mass center where the thrusting load was applied.

After the re-centering, in the second test the structure was pushed up to a mean displacement of $150.7 \mathrm{~mm}$ by a single pushing cycle (Fig. 6). During the lateral pushing test, after reaching a displacement of about $30 \mathrm{~mm}$, the structure exhibited a rotation due to an interference. A careful inspection showed the presence of a hydraulic jack used for the re-centering operations left in place. After the removing, the structure was repositioned to the right configuration, continuing the lateral pushing test. It can be observed that the friction force at the first detachment, as expected, is the typical one exhibited by friction systems that have already experienced previous first detachment. Therefore, an initial resisting forces lower than that detected in the first test was exibited. Specifically, the force coincides with that obtained from the idealized model derived from the first test.

In both tests, the weight of the structure resulted by the using of Eq.(2) where, for $F_{R}$, the difference between the forces observed in the final and initial points of the linear ascending branch of response has been used. Consequently, a weight of $28500 \mathrm{kN}$ (slightly higher than $25000 \mathrm{kN}$ previously assumed) was obtained. Then, the friction coefficient at the first detachment (evaluated considering that the friction force $F_{f}$ assumes the expression $F_{f}=W_{x} \mu$ ) resulted of 0.045 and the static friction coefficient during the test resulted meanly 0.036 . 


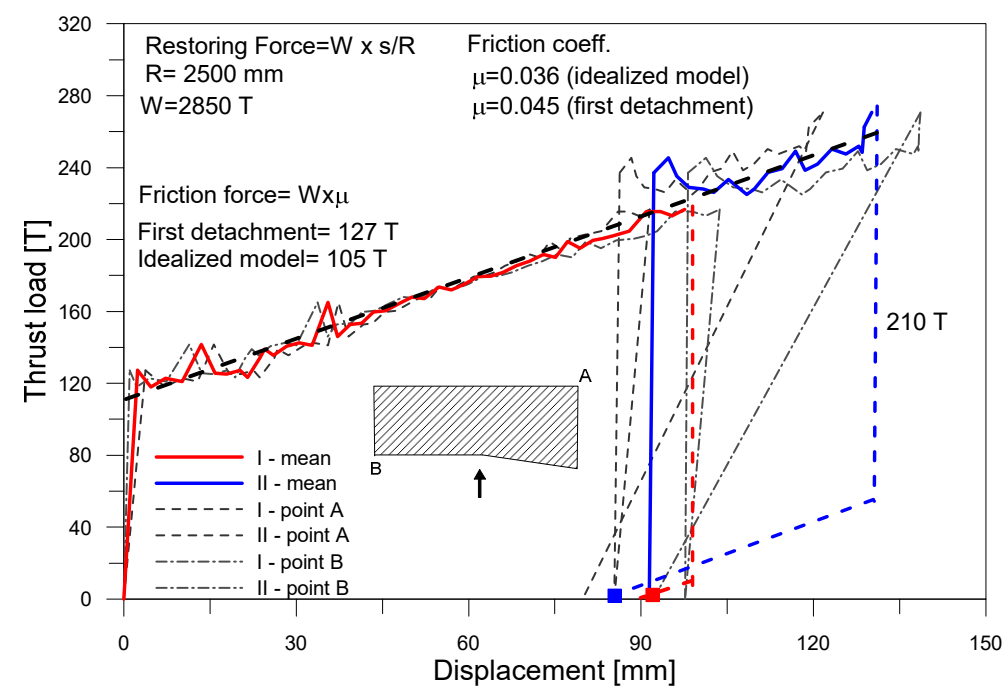

Figure 5: First quasi-static test: two-loading-unloading cycles.

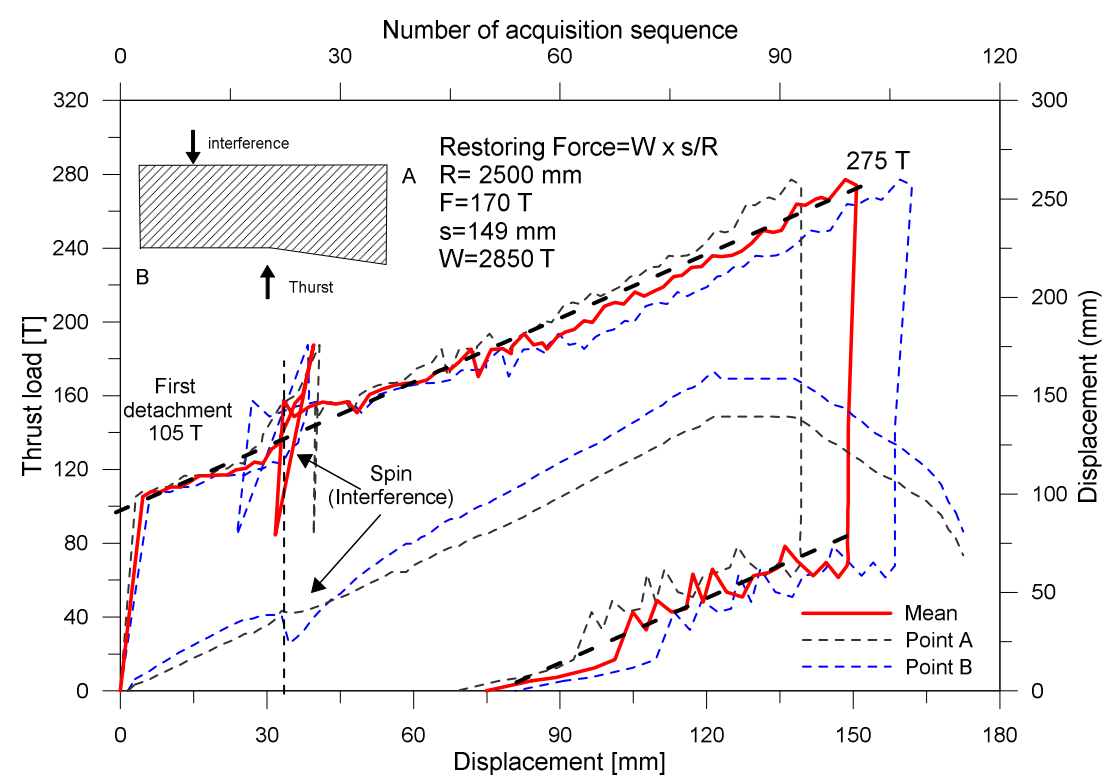

Figure 6: Second quasi-static test: single-loading-unloading cycle.

\subsection{Results: snap-back tests}

Two release tests were carried out to determine the average dynamic friction coefficient of the system and the capability of re-centering. The quasi-static lateral pushing tests made it possible to characterize the system and to evaluate the forces necessary for the displacement to have a reliable prediction of the behavior of the structure at the time of the release test and to design the fuse element in such a way to obtain its failure at the desired displacement.

Given that, for the acquisition of the necessary information for the dynamic characterization of the system, a lower range of displacements with respect to the serviceability limit state was computed as still valid and efficient, it was decided to perform the snap-back tests at a displacement of $120 \mathrm{~mm}$. While during the first one test the structure was released at this displacement, during the second test the release happened at a displacement of $95 \mathrm{~mm}$ for an anticipated collapse of the fuse element. 
In order to obtain a sudden release of the structure in correspondence with the desired displacement, being the fuse a high strength steel rebar, the latter was previous yielded by means of a traction test machine in order to switch its behavior from ductile to fragile. In Fig. 7, a picture of the device before and after failure is represented.

In Fig. 8 a-c, the results of the two snap-back tests are shown in terms of timedisplacement, velocity and accelerations. The derivative operations were carried out after having further filtered and discretized the records for the elimination of disturbances from which the signal was affected.

In the first test (initial displacement $\mathrm{d}_{0}=121 \mathrm{~mm}$ ), the acceleration obtained after discretization resulted of $-88 \mathrm{~mm} / \mathrm{sec}^{2}$, considerably different from that recorded from the pure signal that was $-200 \mathrm{~mm} / \mathrm{sec}^{2}$ (acquisition frequency of $170 \mathrm{~Hz}$ ). These two values were considered as bounds for the evaluation of the friction coefficient at time of release. By multiplying the two values of acceleration for the weight of the structure, the overall inertia forces at the time of release resulted of $-250,8 \mathrm{kN}$ e $-570 \mathrm{kN}$. By means of Eq. (7), the two friction coefficient obtained are 0.028 and 0.039 that are in agreement with those obtained during the quasi-static tests.

In the second test, the acceleration at the moment of release resulted of $-100 \mathrm{~mm} / \mathrm{sec}^{2}$. In this case, the overall inertia force was of $-285 \mathrm{kN}$ and the related friction coefficient at the moment of release was 0.028 .

The average dynamic friction coefficient exhibited during the test was obtained by the energy balance expressed in Eq. 8 considering the overall history from the moment of release to the stop of the structure. In the energy balance, the energy dissipated because of viscosity by the system due to the small oscillations around the rigid base was reasonably neglected. As a result, the dynamic average friction coefficients obtained from the two snap-back tests were 0.02 and 0.017 . These two values are lower than the minimum value declared by the manufacturer (0.025) and adopted for the of design calculations, indicating the need of reassessment of the seismic behavior of the structure after the field testing in order to obtain a more realistic prediction under the design seismic loads.

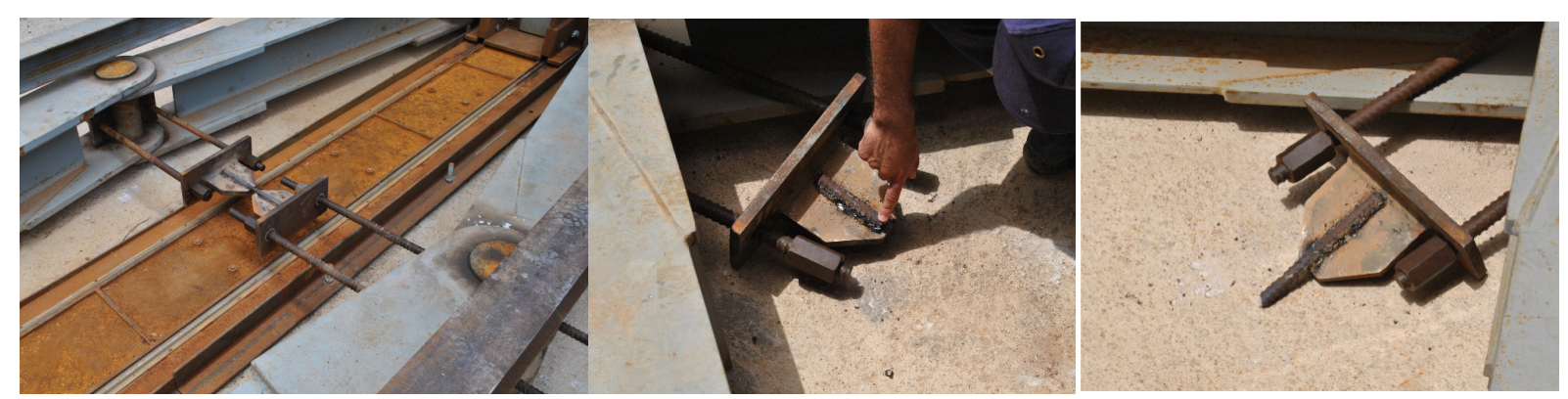

Figure 7: Fuse device before and after failure. 


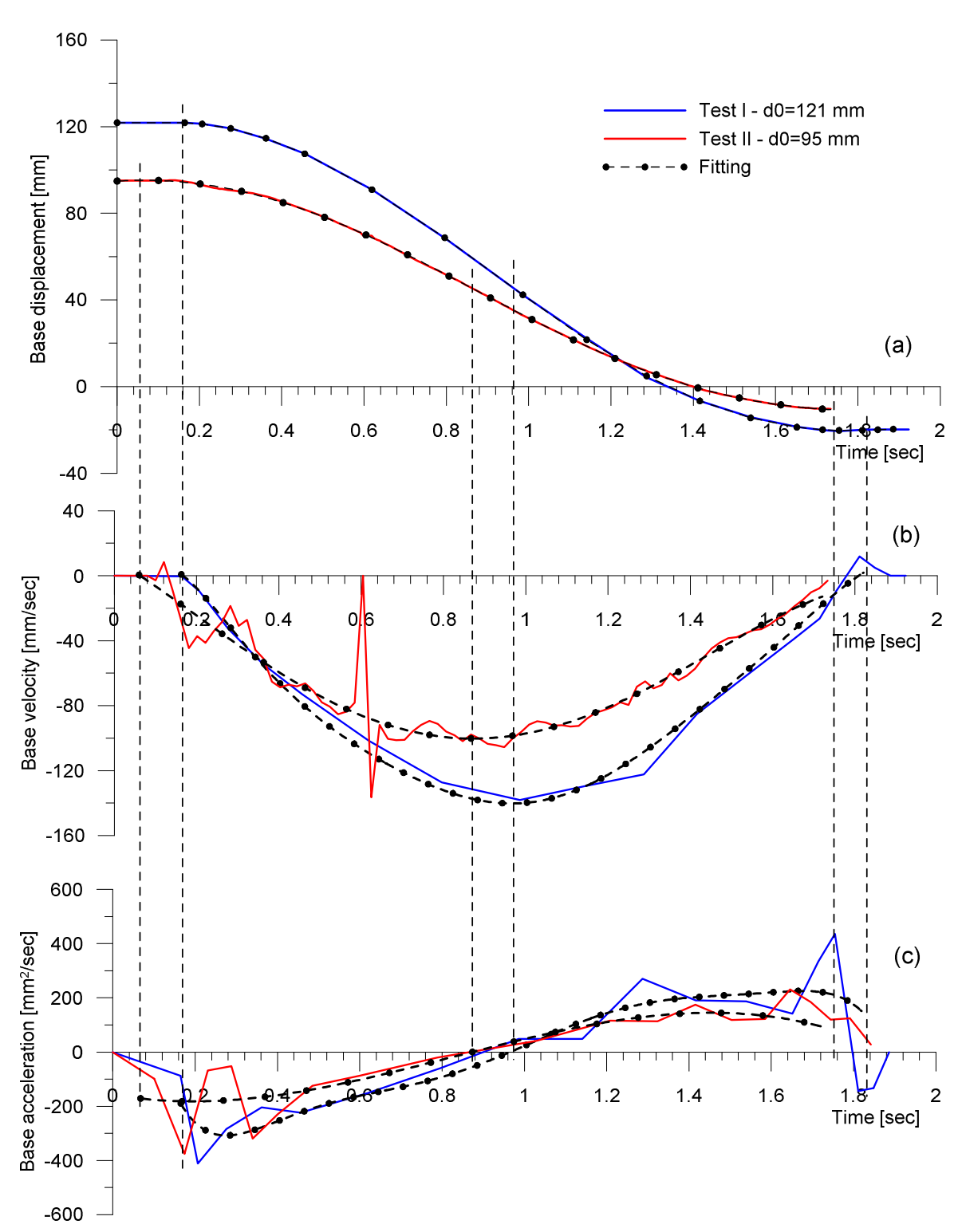

Figure 8: Snap-back tests. Time-displacement records (a), velocity (b) and acceleration (c) derivations.

\section{CONCLUSIONS}

The quasi-static and the snap-back tests had a key role in the definition of the mechanical characteristics of the isolation system. The results and their consequences can be summarized as below:

- the quasi-static and dynamics tests allowed the identification of the static and dynamic friction coefficients to be compared with those used for the design and / or to be used to update the calculation and the safety assessment;

- the value of the static friction forces allows the definition of the re-centering forces to be applied to avoid the dangerous effects of aftershocks on a structure not centered;

- The value of the dynamic friction coefficients allow a reliable assessment of the forces in the superstructure members being 1 ) the use of higher values not conservative for the superstructure and for the design of the joints with the fixed close constructions, 2) the use of lower values not conservative with respect to the assessment of the possible residual displacement after a seismic event; 
- the quasi-static tests have allowed the estimation of the actual mass of the structure;

- the structure showed a torsional behavior due to the not coincidence of the center of masses (where was applied the pushing force) and the center of the stiffness probably for a not equal value of the friction coefficient of each isolator; this fact derives from a not uniform distribution among the isolators of the ratio between vertical applied load and vertical load capacity;

- the structure exhibited a residual displacement during the quasi static tests up to $8-9 \mathrm{~cm}$, meaning that the structure may be in equilibrium at a position far from the position of exercise with high risk in the case of aftershock;

- the re-centering of the structure in its original configuration did not take place naturally because of friction but required the use of hydraulic jacks through the external intervention of high qualified staff.

\section{REFERENCES}

[1] P. Clemente, A. Martelli, Seismically isolated buildings in Italy: State-of-the-art review and applications, Soil Dynamics and Earthquake Engineering, 119, 471-487, 2019.

[2] P. Castaldo, G. Mancini, B. Palazzo, Seismic reliability-based robustness assessment of three-dimensional reinforced concrete systems equipped with single-concave sliding devices, Engineering Structures, 163, 373-387, 2018.

[3] D. M. Fenz, M. C. Constantinou, Spherical sliding isolation bearings with adaptive behavior: Theory. Earthquake Engineering Structural Dynamics, 37, 163-183, 2008.

[4] D. M. Fenz, M. C. Constantinou, Spherical sliding isolation bearings with adaptive behavior: Experimental verification. Earthquake Engineering Structural Dynamics, 37, 185-205, 2008.

[5] P. Castaldo, E. Tubaldi, Influence of ground motion characteristics on the optimal single concave sliding bearing properties for base-isolated structures, Soil Dynamics and Earthquake Engineering, 104, 346-364, 2018.

[6] F. Naeim, J.M. Kelly, Design of seismic isolated structures: from theory to practice. John Wiley \& Sons Inc; 1999.

[7] P. Clemente, G. Buffarini, Base isolation: design and optimization criteria. Seismic Isolation and Protection Systems, 1, 17-40, 2010.

[8] P. Castaldo, B. Palazzo, P. Della Vecchia, Seismic reliability of base-isolated structures with friction pendulum bearings. Engineering Structures, 95, 80-93, 2015.

[9] A.R. Bixio, M. Dolce, D. Nigro, F.C. Ponzo, F. Braga, M. Nicoletti, Repeatable dynamic release tests on a base-isolated building. Journal of Earthquake Engineering, 5, 36993, 2001.

[10] M. Dolce, D. Cardone, D. Nigro, F.C. Ponzo, A.R. Bixio, The behavior of SMA isolation system during the full-scale release tests of the Rapolla's building. In: Proceedings of the 5th world congress on joints, bearings and seismic system for concrete structures. Rome, Italy, October, 7-11, 2001. 
[11] F. Braga, M. Laterza, Field testing of low-rise base isolated building. Engineering Structures, 26, 1599-1610, 2004.

[12] D. Cardone, M. Dolce, F.C. Ponzo, The behaviour of SMA isolation systems based on a full-scale release test. Journal of Earthquake Engineering, 10, 815-42, 2006.

[13] N.D. Oliveto, G. Scalia, G. Oliveto, Time domain identification of hybrid base isolation systems using free vibration tests. Earthquake Engineering and Structural Dynamics, 39, 1015-38, 2010.

[14] G. Oliveto, A. Markou, The dynamics of a pushing and quick release device for dynamic testing of seismic isolated buildings. In: Proceedings of the 2ECEES: second European conference on earthquake engineering and seismology. Istanbul; Aug. 25-29, 2014.

[15] Y.M. He, Y.Q. Yang, J.W. DAI, Field Dynamic Test for A Base-Isolated 15-Story Steel Structure. In: $6^{\text {th }}$ International Conference on Advances in Experimental Structural Engineering, $11^{\text {th }}$ International Workshop on Advanced Smart Materials and Smart Structures Technology., University of Illinois, Urbana-Champaign, United States, August 1-2, 2015.

[16] G. Gesualdi, D. Cardone, G. Rosa, Finite element model updating of base-isolated buildings using experimental results of in-situ tests. Soil Dynamics and Earthquake Engineering, 119, 422-432, 2019.

[17] G. Campione, L. Cavaleri, F. Di Trapani, G. Macaluso, G. Scaduto, Biaxial deformation and ductility domains for engineered rectangular RC cross-sections: a parametric study highlighting the positive roles of axial load, geometry and materials. Engineering Structures 107, 116-134, 2016.

[18] F. Di Trapani, M. Malavisi, Seismic fragility assessment of infilled frames subject to mainshock/aftershock sequences using a double incremental dynamic analysis approach. Bulletin of Earthquake Engineering, 17, 211-235, 2019.

[19] F. Di Trapani, G. Bertagnoli, M.F. Ferrotto, D. Gino, Empirical equations for the direct defnition of stress-strain laws for fber-section based macro-modeling of inflled frames. Journal of Engineering Mechanics (ASCE), 144,04018101, 2018.

[20] L. Cavaleri, F. Di Trapani, G. Macaluso, M. Papia, Reliability of code proposed models for assessment of masonry elastic moduli. Ingegneria Sismica, 29, 38-59, 2012.

[21] G. Campione, L. Cavaleri, F. Di Trapani, M.F. Ferrotto, Frictional effects in structural behavior of no end-connected steel-jacketed RC columns: experimental results and new approaches to model numerical and analytical response. Journal of Structural Engineering (ASCE), 143(8):04017070, 2017.

[22] M.F. Ferrotto, O. Fischer, L. Cavaleri, A strategy for the finite element modeling of FRP-confined concrete columns subjected to preload, Engineering Structures, 173, 1054-1067, 2018.

[23] M.F. Ferrotto, L. Cavaleri, M. Papia, Compressive response of substandard steel jacketed RC columns strengthened under sustained loads: from the local to the global behavior. Construction and Building Materials, 179, 500-511, 2018.

[24] R. Greco, Lucchini A., G.C. Marano, Robust design of tuned mass dampers installed on multi-degree-of-freedom structures subjected to seismic action, Engineering Optimization, 47(8), 1009-1030, 2015. 
[25] G.C. Marano, F. Trentadue, R. Greco, Stochastic optimum design criterion of added viscous dampers for buildings seismic protection, Structural Engineering and Mechanics, 25(1), 21-37, 2007.

[26] G.C. Marano, R. Greco, G. Palombella, Stochastic optimum design of linear tuned mass dampers for seismic protection of high towers, Structural Engineering and Mechanics, 29(6), 603-622, 2008.

[27] NTC 2008. Nuove Norme Tecniche per le Costruzioni. Italian Building Code, 2008. 